International Zoo Yearbook, 7: 215-220

Published by the Zoological Society of London

I967 


\title{
The dugong
}

Dugong dugon (Müller)

\section{its present status in the seas round India with observations on its behaviour in captivity}

\author{
S. JONES \\ Central Marine Fisheries Research Institute, Mandapam Camp, India
}

That sea-nymph's form of pearly light

Was whiter than the downy spray,

And round her bosom, heaving bright,

Her glossy yellow ringlets play.

$$
\text { John Leydon }
$$

It doubtless might please God to make a mermaid, but I don't believe God ever did make one.

$$
\text { Sir Humphrey Davy }
$$

One of the most interesting marine mammals about which very little is known is the dugong or 'sea cow', Dugong dugon (Müller). Though it is an innocuous animal, man has spared neither its reputation nor its peaceful existence. Fiction and imagination have spun such fantastic tales about this creature that to anyone thinking in terms of mythology or folklore, it would be surprising to realise that so much has been made of so little when confronted with a living 'mermaid'. Reference to the two dugongs in captivity at Mandapam Camp as 'mermaids' in the English newspapers and the subsequent literal translation of this in local languages created such a sensation that it roused the curiosity of many. People trekked long distances, hoping to see creatures as depicted by artists, only to return disappointed in what they had seen.

Despite the interest it arouses and despite arm-chair declarations that the dugong is a protected animal, without anyone knowing or caring how to implement this protection, its fate remains unchanged. The capture of a dugong is nothing strange to the ignorant and indigent fisherman, who is more immediately concerned with his own survival than with the ethics of 
protecting a rare animal. Modern fishing gear also plays its part in the gradual attrition of the species. While in the past the dugong only had to contend with cotton or hemp nets, which it was often able to out-manoeuvre successfully, with nylon nets the chances of escape for a dugong caught in one are decreasing. The prospect of early extermination of the species therefore appears greater now than ever before.

The dugong has a fairly wide distribution in the tropical Indo-West Pacific. It is possible that in some places it has already been exterminated by man. According to Ellerman and MorrisonScott (I95I), it has been recorded from the seas of Portuguese East Africa, Madagascar, Mafia Island (off Tanzania), Kenya, the Red Sea, coasts of India and Ceylon, the Andaman Islands, Mergui Archipelago, Ryukyu Islands, Formosa, Malaysian seas, Philippine Islands and Northern Australia. It has also been reported from the island groups of the Philippines, New Guinea, Arakan Sea (near Akyab in Burma), and as far east as the Caroline, Solomon and Marshall Islands and New Caledonia ${ }^{1}$ (MacMillan, ${ }^{1955) .}$ According to Hirasaka (I934) there are unconfirmed reports of its capture from the eastern shore of Kyushu in Japan, and off Gunsan, near Chosen in Korea.

In the seas round India it is found in the Gulf of Mannar and Palk Bay, both along the coasts of India and Ceylon (Figure I), in the Gulf of Cutch and in the Andaman Sea. Reference to the Malabar Coast in Ellerman and Morrison-Scott (195I) might be based on specimens that had strayed into the area, presumably from the Gulf of Mannar as there does not appear to be any local dugong population there. The entire coast is surf-ridden and lacks calm and shallow areas where sea grass, the dugong's staple diet, could grow. Though there are records of dugongs occurring in the Gulf of Cutch during the last century (vide Moses, I 942) it is only in recent years that some authentic records have become available (Mani 1961, Silas 1961, Mohan 1963).

The Gulf of Mannar and Palk Bay could rightly be considered the home of the dugong in the Indian region. According to reports, sea cows abounded in these areas about a century ago. The most authoritative account of the dugong in this area is given by Annandale (1905) who says that 'it is rare nowadays for more than one specimen to be taken at a time, whereas formerly in the Gulf of Mannar flocks of many hundreds were said to occur. Further, the animal appears to have ceased to frequent shallow water, for, according to the fishermen, the only specimens they see near the shore are those which have been wounded or are sick.' If this was the situation 60 years ago the extent to which the species has been depleted within this period can very well be imagined.

The situation is the same if not worse on the opposite side, along the coast of Ceylon, bordering the Gulf of Mannar and Palk Bay. Here the demand for dugong meat is so great and the price so high that the fisherman scour the area and catch any that they find, especially along the Jaffna coast. Very little is known about the migratory habits of the species, but it is probable that intermingling of different populations occurs along both coasts. Palk Bay is like an inland sea and is nowhere deeper than 9 to ro fathoms. There are extensive beds of sea grass in the shallow coastal belts and therefore the movement within the area should be considerable. There should also be intermingling of the dugongs in the Palk Bay with those in the Gulf of Mannar through the Pamban Pass (between the mainland and Rameswaram Island), and through the gaps in the coral reef forming the Adam's Bridge between Rameswaram Island and Ceylon.

In the Gulf of Mannar there is a chain of islands, with the Rameswaram Island in the northeast off Mandapam and Punnaiyadi, and Pandyan Islands in the west off Tuticorin (Figure I). Round Musal Island, off Mandapam Camp, and Appa and Balayamunai Islands, off Kilakarai, there are extensive beds of sea grass and this area forms the main grazing ground for dugong, on the Indian side of the Gulf of Mannar. Both the dugongs in the Institute's aquarium at Mandapam Camp were caught here. It is said that when heavy winds blow from the southwest the dugong moves to the lee-side, between the islands and the mainland, and the movement is reversed when the wind changes to the northeast during the monsoon period. It would be interesting to find out

${ }^{1}$ A female dugong was kept alive for four months at Nouméa Aquarium in 1965 . It measured $\mathrm{r} \cdot 60 \mathrm{~m}$ long and weighed $60 \mathrm{~kg}$. It was fed on marine plants (Cymodocea and Halophila). The cause of death was pneumonia (R. Catala-Stucki, I966 : personal communication to C. Jarvis.) 


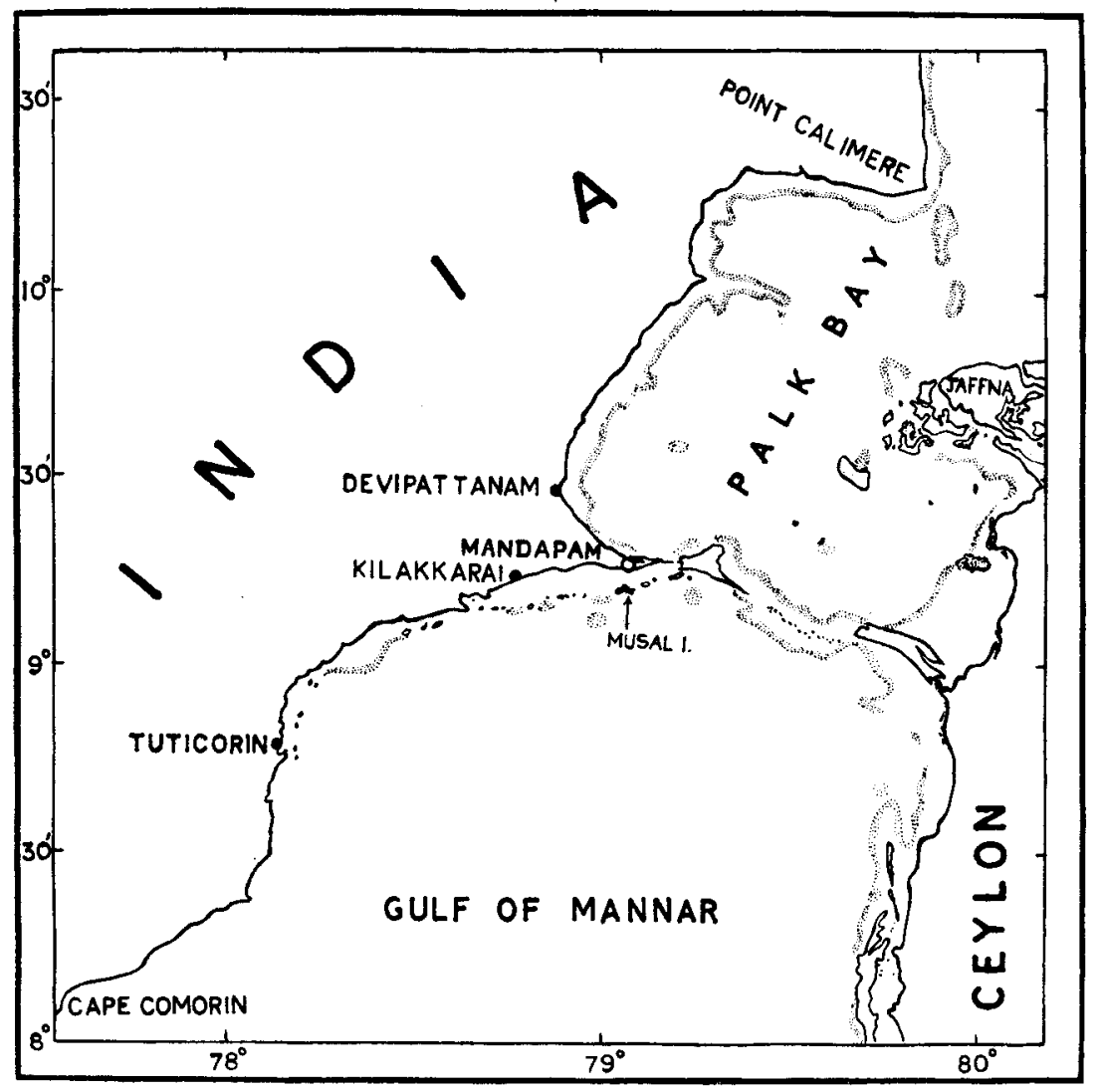

Figure I. Map showing the Gulf of Mannar and Palk Bay.

whether there is a coast to coast movement of dugong between India and Ceylon.

A great reduction in the number of dugongs has been reported along the Indian coast of Palk Bay during the last to years, after the cyclone in December 1954. It was accompanied by very heavy rains which flooded the whole region, lowering the salinity of Palk Bay considerably. According to fishermens' reports, large numbers of dugongs were found dead, washed ashore, a few days afterwards and since then they have been seen only very rarely. They attribute the mortality to the lack of food as all the sea grass died with the influx of fresh water. It is however difficult to believe that the dugong would die so quickly for lack of food and there may be another cause for their death, such as infection brought about by the low salinity. No such mortality has been reported from the Gulf of Mannar at any time nor from the Palk Bay area during the cyclone of December 1964, which was accompanied by a devastating tidal wave.

Fishing for dugong is still carried out both along Palk Bay and the Gulf of Mannar, though the catches are reported to have diminished considerably during recent years. They are caught in nets specially set for them or accidentally in nets set for fish or turtles as described elsewhere (Jones, $\mathrm{m} / \mathrm{s}$ ). They are not killed with spears as is done in the Pacific.

The meat is in great demand among the local population, especially among Muslims, who form the majority along the coastal belt and for whom pork is a religious taboo. The main market for dugong meat is Kilakarai on the Gulf of Mannar where the fishing intensity is at its maximum at present. In some places in the Palk Bay area they are kept for a few days in saline water ditches near the shore till they are purchased by merchants. The meat is reported to compare favourably with 


\begin{tabular}{|c|c|c|}
\hline & $a^{\pi}$ & 우 \\
\hline Total length (tip of snout to fork of tail) & $205 \cdot 3$ & $213^{\circ} 0$ \\
\hline Length of muzzle & $18 \cdot 8$ & $20 \cdot 2$ \\
\hline Width of muzzle & I $5 \cdot I^{*}$ & $16 \cdot 5^{*}$ \\
\hline Length of flippers (axilla to tip) & $36 \cdot 4 *$ & $36 \cdot 4$ \\
\hline Width of flippers (maximum) & $18 \cdot 0$ & $18 \cdot 5$ \\
\hline Circumference of belly (resting on floor of tank) & $148 \cdot 8$ & $557^{\circ} 9$ \\
\hline Distance between tips of tail flukes & $66 \cdot 1$ & $63 \cdot 0 \dagger$ \\
\hline
\end{tabular}

* Not precise. Accurate measurements were difficult because of movement. $\uparrow$ Deformed.

Table I. Measurements of two dugongs Dugong dugon at Mandapam Camp. The dugongs were caught in October and December 1959 and the measurements taken on 21 June r966.

soft beef and fetches about the same price. When several are available at the same time, whatever meat is not sold fresh is salted. Though the fishermen do not believe, as the Malays do, that the dugong 'tears' are a powerful aphrodisiac, the meat is supposed to have medicinal value and some even believe that it has rejuvenating and aphrodisiac properties.

The largest dugong on record is one reported by Mani ( 1960 ) as being $4.06 \mathrm{~m}$ long and is said to have weighed one ton. Usually specimens found in the Gulf of Mannar and Palk Bay measure 2 to $3 \mathrm{~m}$ long, the larger ones measuring 2.5 to $3 \mathrm{~m}$. The smallest specimen obtained in recent years was a female $\mathrm{I} \cdot 06 \mathrm{~m}$ long and weighing $20 \mathrm{~kg}$. A male measuring $2.75 \mathrm{~m}$ long weighed $380 \mathrm{~kg}$, and another male measuring $2.47 \mathrm{~m}$ long weighed $280 \mathrm{~kg}$. The two animals kept at Mandapam Camp have never been weighed.

Details of the two dugongs kept at Mandapam Camp have already been published (Jones, 1959) and need not be repeated here. It would seem that they have now established a longevity record for the species in captivity as they have now been at our aquarium for $6 \frac{1}{2}$ years. Together they eat 50 to $60 \mathrm{~kg}$ (wet weight) of sea grass daily. In December 1959 they each measured 160 and 196 $\mathrm{cm}$ long, and in June $1966,205 \cdot 3$ and $213 \mathrm{~cm}$ long. The increase in length has not been proportionate and at present we have no comparative information on growth rate of dugongs in the wild. Additional measurements are given in Table $r$.
The dugongs at Mandapam Camp are shy and appear to be rather less intelligent than dolphins. There has been hardly any change in their behaviour and they do not appear to recognise the people who feed them. They have become so tame that they now take food from the hand without fear. The tank is cleaned and the water changed once daily at high tide and the animals move actively about the tank as the fresh water flows in. Unfortunately the water is barely $\mathrm{I} \mathrm{m}$ deep and therefore freedom of movement is restricted. They can only make horizontal movements and they are unable to assume a vertical position. Differentiation of the sex when viewed from above is not possible and the tusks of the male, though larger than the female's, cannot be seen externally. The male is usually more active than the female and struggles vigorously when any attempt is made to measure or separate him from the female. When the tank is emptied of water and the dugongs are exposed to the air, a viscous fluid comes out of their eyes. Neither the dugong nor the manatee (Trichechus) has a lachrymal duct, so that the secretion of the gland spills over the eyelid when the animals are out of water to wash the excess away. In the female at Mandapam Camp the flow is continuous, while in the male the fluid is only secreted in driblets.

During their six years at Mandapam Camp the dugongs have become so attached to each other that it is almost impossible to separate them. They always move about together and any attempt to 
separate them makes them restless. They struggle vigorously until they are side by side again. The male seems to be more active and is more sensitive to separation than the female. $\mathrm{He}$ is also more active in trying to prevent separation. When the tank is emptied, the dugongs tend to remain close together, lying head to head. They seem to see well since whenever they are separated while the tank is cleaned or when they are photographed, they continue to struggle until they are lying side by side again. Out of the water they have to make considerable effort to achieve this, by beating down with the tail and raising the fore-part of the body with the help of the flippers preparatory to moving forwards.

Though the dugongs have been seen occasionally nudging or even chasing each other in the tank, anything that could be described as courtship display or attempted mating was not noticed until April r966. Observations were made by my colleague, Dr P. S. B. R. James, who kindly passed on the information to me. His observations are given briefly below.

The pair was noticed actively swimming in the tank at 0845 hours on 8 April 1966 . The male turned so that his belly was uppermost. He moved forward and remained in this position for two or three minutes. Occasionally he approached the female, pushing and biting her neck. Both moved vigorously, splashing water with their tail flukes. The weather was cool and the sky overcast at that time. The activity continued until late at night. The male's penis was seen projecting 5 to $8 \mathrm{~cm}$ from the body and was light pink. Spurts of activity continued the following day. At 1730 hours on 9 April I 966 the female also turned upside down, and then both animals rolled together from side to side. It was noticed that the male had an injury near the mouth and that it was bleeding slightly, presumably as the result of the extreme activity. The following day there was no courtship activity and they fed calmly. No observations were made on ro April but on $\mathrm{r}$ I April the dugongs were very active between I930 and 2130 hours. The male 'bit' the female and then turned across her; at the same time he turned upside down. Immediately afterwards they separated. This was repeated and after some time the female appeared exhausted and sluggish, with her flippers hanging down. After this they fed for some time. No activity was seen on 12 April but a number of abrasions were noticed on the skin of both animals. No observations were made on $I_{3}$ and I $_{4}$ April, but on $\mathrm{I}_{5}$ April at 233o hours the dugongs were again active. After this they remained calm as usual.

On several occasions we have examined a number of dead dugongs caught in this area and the large ones, particularly the males, invariably had conspicuous scars on them. It is possible that many of these could have been caused during the mating season, either from females or from competing males.

Dugongs have never been known to make any sound audible to the human ear.

The female dugong at Mandapam Camp developed some white blisters in patches on the tail fluke in April r964. These were treated successfully with sulfa-ointment, leaving only white marks which are still visible. The water circulation in the aquarium is far from satisfactory and considering the adverse conditions under which the dugongs have survived, it would appear that the dugong is a relatively hardy animal.

In addition to the two dugongs still alive, two more were obtained, but these only survived for a few months. In one, postmortem examination revealed a detached sting of a ray, about $7 \mathrm{~cm}$ long, lying attached to the peritoneum within the abdomen, immediately below the liver. A callous area, filled with lymph-like fluid, was found round the spine and it is possible that death may have been caused by this injury. It is probable that while grazing the dugong accidentally came into contact with a large ray resting on the sea bed which, in its fright, would have stung the dugong before moving off. Another possibility is that on some previous occasion it might have become entangled in a net and during its struggle to escape was stung by a ray, also entangled in the same net. It is reported by local fishermen that the sting ray Dasyatis sephen lashes its tail at the slightest provocation and during this process the sting often becomes detached and embedded in the body of its victim.

The second animal which died was a male which, at postmortem, was found to have inflamed testes filled with pus, probably as the result of injuries received at the time of capture.

In conclusion it may be said that it is unfortunate that our knowledge of the dugong's biology and behaviour remains almost as meagre and 
imperfect as it was half a century ago. However, credit should be given to the Marine Biological Association of India for the interest created in the study of this animal by the organising of the Dugong Research and Conservation Fund. Although this did not receive the response it deserved and the project could not be realised, it is hoped that the interest that has been created will be sustained and will lead to the initiation of comprehensive research, under an international programme, on this interesting animal in the Indo-Pacific.

\section{REFERENCES}

ANNANDALE, N. (1905): Notes on the species, external characters and habits of the dugong, $\mathcal{f}$. Proc. Asiat. Soc. Bengal (NS), r: 238-243.

ELLERMAN, J. R. and MORRISON-SCOTT, T. C. S. (I95I) Checklist of Palaearctic and Indian mammals, 1758-1946. London: British Museum.

gohar, H. A. F. (1956): The Red Sea Dugong. Pub. Mar. Biol. Stn. Al-Ghardaqua (Red Sea), 9: 3-5o.
HARRY, R. R. (1956): 'Eugenie' the dugong mermaid. Pacific Discovery, 9, (I): 2I-27.

HIRASAKA, K. (1934): On the distribution of Sirenians in the Pacific. Proc. 5 th Pacific Sci. Congr. Victoria ES Vancouver BC, Canada, 1933: 4221-4222.

JONES, S. (I959): On a pair of captive dugongs Dugong dugong (Erxleben). F. Mar. Biol. Ass. India, r, (2): $198-202$.

JONES, s. The dugong fishery of the Gulf of Mannar and Palk Bay. (Unpublished $\mathrm{m} / \mathrm{s}$.)

MaCmillan, L. (I955): The dugong. Australian Geogr. Walkabout Mag., 21 (2): I7-20.

MANI, S. B. (1960): Occurrence of the Sea Cow, Halicore dugong (Erxl), off the Saurashtra coast. 7 . Bombay nat. Hist. Soc., 57 (1): 216-217.

MOHAN, R. S. LAL. (1963): On the occurrence of Dugong dugon (Müller) off the Gulf of Cutch. 7. Mar. biol. Ass. India, 5 (I): 152.

MOSES, S. T. (I942): The fisheries of the Gujarat coast. 7. Gujarat Res. Soc., 4 (2): 75.

POCOCK, R. 1. (1940): Some notes on the dugong. Ann. Mag. nat. Hist., 5 (I I): 229-245.

Prater, S. H. (1928): The dugong or Sea Cow (Halicore dugong), 7. Bombay nat. Hist. Soc., 33 (1): 84-99.

SILAS, E. G. (rg6r): Occurrence of the Sea Cow, Halicore dugong (Erxl.), off the Saurashtra coast. 7. Bombay nat. Hist. Soc., 58 (I): 263-266. 